\section{Entre tensões e escolhas, um olhar sociológico sobre jovens na vida religiosa}

Silvia Regina Alves Fernandes ${ }^{1}$

Resumo: $O$ artigo analisa a juventude contemporânea a partir do eixo religiosidade e adesão religiosa a institutos católicos. A primeira parte do texto apresenta dados secundários sobre o perfil dos jovens e demonstra que o trabalho e o estudo são demandas importantes para esse segmento. Os jovens brasileiros manifestam ainda crença na mudança social. Com base em dados de pesquisa quantitativa com jovens religiosos na Baixada Fluminense e dados primários sobre jovens que aderem ao Instituto Toca de Assis, no catolicismo, argumenta-se, na segunda parte do artigo, que estes últimos, a partir de seus ideários de pobreza e recusa ao conhecimento, podem representar contestação à situação do jovem na sociedade brasileira. Compara-se as diferentes formas de adesão a institutos religiosos e sugere-se que a Toca de Assis, a despeito do processo de institucionalização que atravessa, tem contestado a Vida Religiosa de institutos tradicionais e seus mecanismos de poder e se apresenta como um objeto empírico relevante para a análise das novas sensibilidades religiosas juvenis.

Palavras-chave: Juventude Contemporânea, Vida Religiosa, Catolicismo, Poder, Toca de Assis.

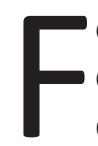

oi-se o tempo em que pertencer a uma ordem ou congregação religiosa católica significava, necessariamente, afastamento ou isolamento do mundo. Do mesmo modo, longínquo é o tempo em que as famílias sonhavam com filhos padres e/ou filhas piedosas vivendo reclusas em uma casa conventual. Esse tipo de escolha é cada vez mais confrontada no ambiente familiar e exige dos pais de camada média uma razoável capacidade de abdicação dos sonhos profissionais ou pessoais que planejaram para seus filhos. Do mesmo modo, os pais de camada socioeconômica menos favorecida que se defrontam com um filho ou uma filha desejosos de ingressar em seminários ou institutos religiosos se veem diante de uma realidade que representa abdicação de quem poderia contribuir no sustento da família ao alcançar a idade laboral.

$\mathrm{Na}$ sociedade brasileira, os jovens que ingressam na Vida Religiosa $(V R)^{2}$, em geral, possuem maior faixa etária - e essa regra vale para rapazes e moças -; adotam estilo de vida modesto, estudam, atuam em pastorais ligadas ao catolicismo e podem confundir-se com outros jovens não religiosos
Recebido:

29/10/10

Aprovado:

8/07/11

1. Professora do Programa de Pós Graduação em Ciências Sociais (UFRRJ). E-mail:

fernandes.silv@ gmail.com

2. Denomino de VR as instituições de caráter ativo e contemplativo da Igreja Católica que recebem rapazes e moças dispostos a tornarem-se padres/religiosos ou freiras, respectivamente. Essas instituições - que também possuem diferenças internas - distinguem-se dos modelos de comunidades de vida e de Institutos, tais como os Filhos e FiIhas da Pobreza do Ssmo. Sacramento, reconhecido como Toca de Assis e que será abordado na segunda seção deste texto. 
3. Por mera questão de espaço, não adotarei, neste texto, a distinção de gênero. Leia-se, portanto, a categoria jovens como representativa de rapazes e moças. dependendo do modo como costumam vestir-se (com ou sem hábito religioso). A escolha do uso ou não do hábito revela, também, a cosmovisão e os significados que esses jovens atribuem à própria inserção institucional e à sua consequente presença nos diferentes contextos sociais. A vestimenta revela, ainda, se os jovens desejam ou não enfatizar os sinais distintivos de sua condição.

Todavia, há algumas décadas, a Igreja Católica, em todo o mundo, vem acompanhando o declínio de candidatos e candidatas à VR, ou no jargão institucional, a "crise de vocações". Esse fato tem sido analisado como a consolidação do processo de secularização que atinge primeiramente a Europa, mas que possui reflexos bastante intensos nas Américas, guardando-se as especificidades da América do Sul, marcada tanto pela diversidade religiosa, quanto pela ação de missionários advindos de vários países da Europa ocidental e que, em tempos passados, fomentaram a adesão à VR em diferentes regiões do Brasil.

Sublinhe-se que a história da Vida Religiosa deve levar em conta o caráter heterogêneo da implantação de ordens e congregações europeias no país, bem como os diferentes contextos históricos que as abrigaram: a cristandade colonial e sua crise, o período denominado de romanização e, por fim, o período da renovação pastoral. Atualmente, a essa cronologia - trabalhada por historiadores da Igreja, tais como Riolando Azzi (1983) - pode ser agregado o novíssimo e inquietante contexto das novas comunidades religiosas, de caráter fortemente carismático e espiritualista e que, certamente, se instaura como um desafio para a VR tradicional, aqui compreendida como as congregações e ordens instituídas por figuras históricas reconhecidas pelo Vaticano, como, por exemplo, Francisco de Assis, Vicente de Paulo, Clara de Assis, etc.

Na primeira parte desse texto, objetivo traçar um breve perfil dos jovens ${ }^{3}$ brasileiros, de modo a oferecer chaves de leitura para as escolhas que alguns deles têm feito no campo aqui abordado, ou seja, nas diferentes formas de Vida Religiosa. $\mathrm{O}$ avanço das novas comunidades religiosas de espiritualidade carismática e os desafios que trazem à VR tradicional serão analisados na segunda parte do texto e, na última seção, procuro apresentar uma questão crucial experimentada por jovens que escolhem a VR, a saber, o exercício do poder em suas congregações e, consequentemente, nas relações comunitárias.

Certamente, não será possível explorar de forma suficientemente abrangente esses tópicos, mas tenho a expectativa de oferecer aos pesquisadores do tema outras possibilidades interpretativas a respeito das escolhas juvenis para as novas formas de vida consagrada ou, por outro lado, as desistências e tensões experimentadas por vários jovens que atualmente estão inseridos na VR.

A proposta deste artigo é, portanto, demonstrar que a análise da "crise de 
vocações" e das escolhas juvenis para a VR necessita do cotejo dos seguintes temas-problema ou condicionantes: 1) a condição socioeconômica, religiosa e cultural dos jovens na sociedade brasileira; 2) o avanço do carismatismo e das novas comunidades na Igreja Católica e suas implicações para a Vida Religiosa e, por fim, 3) o uso e a construção do poder na VR, temática que tem se constituído como uma das principais fontes de tensão para os jovens que hoje pertencem aos institutos e congregações religiosas no país. O cotejo analítico desses aspectos visa a ultrapassar a mera constatação da existência de "crise de vocações", a partir de parâmetros exclusivamente estatísticos. Além disso, pretendo oferecer elementos para a análise sociológica dos dilemas que estão colocados para a Vida Religiosa, seja no modelo ativo em que mulheres e homens consagrados atuam diretamente em instituições seculares ou em bairros periféricos, seja no modelo contemplativo que pode supor clausura e menor abertura conventual na relação com a sociedade.

\section{Aspectos metodológicos}

Esse empreendimento analítico só me é possível em razão de minha atuação como assessora da Conferência dos Religiosos do Brasil-CRB, para os encontros do Juninter ${ }^{4}$, no Rio de Janeiro, durante os anos de 2006 e 2008; das inúmeras assessorias, análises institucionais e minicursos que prestei a congregações e institutos religiosos, em nível nacional, na perspectiva sociológica; em razão de minhas pesquisas de mestrado e doutorado (FERNANDES, 1999; 2004), cujos temas modernidade, catolicismo e VR estiveram fortemente engendrados; e, por fim, pelo acesso aos dados de minhas últimas pesquisas sobre juventude e religião, às quais farei referência mais adiante.

Este artigo, portanto, faz uso de dados secundários de pesquisas devidamente referenciadas e, ainda, de uma pesquisa recentemente finalizada sobre a Toca de Assis - comunidade religiosa do catolicismo. Essa última pesquisa consistiu na elaboração de diários de campo e entrevistas com rapazes e moças dessa comunidade, principalmente os que moram no Rio de Janeiro. O trabalho de campo foi realizado durante os anos de 2008 a 2010. (FERNANDES, 2011).

\section{O contexto contemporâneo das vocações religiosas}

O estudo multidisciplinar da Vida Religiosa no Brasil não pode prescindir da análise das novas configurações dessa instituição que vem atravessando mudanças nos últimos tempos. Tais mudanças têm sido catalisadas de modo especial pela "crise de vocações" ou pelos novos estilos de padre que irrompem na
4. O Juninter é um encontro de formação de jovens que já fizeram os primeiros votos (pobreza, castidade e obediência) na Vida Religiosa. 
5. Analisei esses números na tese, relacionando-os com o crescimento populacional no período 1970-2000. Cf. Fernandes (2004).
6. O CERIS atravessou forte crise econômica e interrompeu o censo da Igreja. Posteriormente, o trabalho foi terceirizado à Promocat, que vem informatizando a coleta de dados. vida secular, adentrando inclusive no mercado fonográfico. Contudo, ao que os produtores do sagrado denominam "crise de vocações" - tendo como parâmetro, sobretudo o declínio quantitativo de candidatos(as) - devem ser acrescidas outras variáveis relevantes para a compreensão da dinâmica da VR no contexto contemporâneo.

O último levantamento estatístico sobre a VR no país foi realizado há dez anos (2000) pelo Centro de Estatística Religiosa e Investigações Sociais - CERIS e indicou uma tendência de crescimento de seminaristas diocesanos, de estabilidade no número de noviços e de declínio no quantitativo de noviças. Em números absolutos, havia, no ano de 2000, um total de 8.659 seminaristas ligados às dioceses brasileiras e 3.393 vinculados aos Institutos religiosos. Ao todo, no universo masculino, havia, portanto, 12.052 rapazes candidatos à Vida Religiosa e ao sacerdócio diocesano naquele ano. Os números para a VR feminina eram bem mais modestos, totalizando 3.140 moças entre noviças e pré-noviças ${ }^{5}$ em todo o país. As primeiras definem-se pela conclusão da primeira etapa de formação na VR e por estarem mais próximas da efetivação dos votos de castidade, pobreza e obediência, e as segundas podem ser entendidas como simpatizantes da VR e são assim definidas por estarem numa etapa preliminar de inserção institucional.

Esses números, embora defasados, sugerem que a opção sacerdotal estaria em situação privilegiada diante da Vida Religiosa, e mais, as moças estariam cada vez menos interessadas em aderir à vida consagrada. Isso significa dizer que a "crise de vocações" tem se mostrado mais aguda no universo feminino do que no masculino, ao menos no que diz respeito às formas tradicionais de VR, que tanto podem implicar na atuação de religiosos e religiosas na sociedade, quanto no afastamento experimentado pelos que optam pela clausura ou pela vida monástica.

Infelizmente, o censo da Igreja Católica foi interrompido no ano de 2003 e apenas em 2009 foi retomado 6 . É fato, portanto, que não há, no momento atual, números seguros sobre o contingente religioso institucional no Brasil. Esse contingente abrange padres, bispos, freiras e jovens interessados em seguir o sacerdócio ou a Vida Religiosa como irmãos e irmãs.

Apesar dessa defasagem relacionada ao dado quantitativo, estudos etnográficos têm demonstrado que outros modelos de Vida Religiosa exercem atração sobre a juventude sempre em busca de novas experiências, sobretudo sobre a VR feminina. Esses modelos possuem forte inspiração na Renovação Carismática Católica - RCC, movimento inaugurado na cidade de Campinas/SP, em 1968, e que logrou franca expansão a partir dos anos 80 . Assim, muitos jovens ávidos pela espiritualidade carismática passaram a formar comunidades de oração e 
estas ganham vigor e expandem-se a partir de encontros nas casas e, posteriormente, nas paróquias católicas. Os famosos grupos de oração, primeiros núcleos carismáticos, passam então a conviver paulatinamente com as novas comunidades, também originárias de Campinas/SP, e que mais tarde seriam denominadas de Comunidades de Aliança e Comunidades de Vida, no Espírito Santo. Os estudos de Eliane Oliveira (2003; 2009) mostraram as aproximações entre a RCC e essas novas comunidades, que também podem aproximar-se de uma espiritualidade do tipo New Age.

Enquanto nas Comunidades de Aliança os jovens vivem uma vida profissional e pessoal ordinária, sem uma adesão radical à comunidade, nas Comunidades de Vida eles consagram-se inteiramente ao trabalho religioso, conforme demonstrou Cecília Mariz (2009). Exatamente esse segundo modelo comunitário - no qual os jovens adotam os votos religiosos de pobreza, castidade e obediência - apresenta-se como mais ameaçador à VR tradicional, pois se, por um lado, abre à juventude a possibilidade de adesão radical, por outro, permite o desenvolvimento de um tipo de experiência comunitária menos rígido sob o ponto de vista das relações pessoais, o que favorece a manutenção de aspectos próprios à juventude: alegria e espontaneidade.

A VR tradicional, há muito, tem se debruçado em busca da adoção de novas estratégias de sensibilização da juventude para o ingresso em seus institutos religiosos. Não obstante, possuem menor arrojo no recrutamento juvenil e seguem adotando fórmulas pouco eficazes nesse recrutamento, que ocorre tanto por meios das antigas pastorais vocacionais ou, mais recentemente, pela divulgação nos sites da Internet. Além disso, em que pesem as diferenças internas dos institutos religiosos, percebe-se a ocorrência de certo temor, em muitas dessas instituições, frente à possibilidade de mudança estrutural. Sobretudo os institutos religiosos femininos, embora diagnostiquem aspectos emergentes geradores de crises internas, encontram resistências de membros mais antigos no que se refere ao incremento de transformações ou adaptações necessárias à própria sobrevivência.

\section{A(s) condição(ões) juvenil(is) na sociedade brasileira}

Sempre que a temática juventude entra na pauta dos estudos socioantropológicos, a heterogeneidade da categoria é considerada, fato que espelha a impossibilidade de congelar, numa única palavra, os diferentes perfis juvenis. Esses perfis são delineados levando-se em conta as diversificadas inserções locais, regionais e culturais desse segmento social tão rico de possibilidades e, paradoxalmente, tão empobrecido pelas condições sociais precárias que força 
7. A pesquisa utilizou a mesma classificação do Instituto Brasileiro de Geografia e Estatística - IBGE para o mapeamento da cor/raça. seus integrantes, ou seja, os jovens, a desenvolver diferentes estratégias de sobrevivência, visando a garantir a própria inclusão e participação na sociedade.

Se tais condições sociais não podem ser generalizadas para o segmento juvenil, é possível assegurar que uma fatia importante dele não tem sido integrado socialmente através de mecanismos tradicionais de emancipação, como, por exemplo, a inserção laboral. Praticamente todos os dados que apresentarei nessa seção referem-se a uma pesquisa nacional sobre a juventude realizada pela Fundação Perseu Abramo, em parceria com o Instituto Cidadania. Essa pesquisa - de ampla divulgação nacional e cujos dados foram coletados em 198 municípios, no ano de 2003 - abrangeu 3.501 jovens, com faixa etária de 15 a 24 anos, nos ambientes rural e urbano, em cidades pequenas, médias e capitais e abarcou vários temas, com o objetivo de desenhar um amplo perfil da juventude e subsidiar ações governamentais. A coordenação esteve a cargo de Helena Abramo e Pedro Branco (2005).

Vejamos, primeiramente, o perfil sociodemográfico dos jovens brasileiros a partir da pesquisa. 38\% estão na faixa etária de 21 a 24 anos; do conjunto de entrevistados, $52 \%$ possuem o nível médio completo ou incompleto, $42 \%$ estão no nível fundamental e cerca de $6 \%$ possuem o nível superior. Inseridos no mercado de trabalho há $47 \%$ dos rapazes e apenas $25 \%$ das moças na faixa etária de 21 a 24 anos. Há maior proporção de moças (35\%) do que rapazes (29\%) que já trabalharam e estão desempregados e, embora sem realizar o recorte por sexo, a pesquisa mostrou que o mercado informal tem recebido mais jovens (60\%) do que o mercado formal (34\%), fato que demonstra a precarização da inserção laboral para o segmento. Em nível nacional - sem trazer aqui os dados sobre as regiões brasileiras -, a pesquisa mostrou que 31\% (a maior parte dos informantes) possuem uma renda familiar mensal que corresponde à faixa de mais de 2 a até 5 salários mínimos, contudo há $24 \%$ cuja renda familiar mensal não ultrapassa 2 salários mínimos e as outras percentagens contemplam faixas de renda ainda menores. Esse dado mostra que uma significativa parcela da juventude atual necessitará trabalhar se quiser ter acesso a bens elementares e à educação de qualidade, não podendo depender apenas de recursos familiares e, eventualmente, terá de fazer a escolha entre estudo e trabalho. Quanto à cor/raça ${ }^{7}$, a maioria afirmou ser branca, $44 \%$; $25 \%$ se declararam pardos; $17 \%$ pretos; $5 \%$ indígenas; $4 \%$ de cor amarela e $4 \%$ declararam ser de outra cor diferente das sugeridas no questionário.

Em síntese, os dados sociodemográficos sugerem média escolarização, médio rendimento e baixa inserção laboral. Como dito anteriormente, embora consideremos a heterogeneidade da juventude, a pesquisa revela a existência de um perfil social mais universal referente a esse segmento, que pode ser identificado pelas características acima descritas. 
Vejamos algumas questões relacionadas ao perfil sociocultural e aos valores da juventude investigada. Quanto à religião, a maioria - mas não uma maioria esmagadora - declarou-se católica (65\%); 22\% são evangélicos (15\% pentecostal, $5 \%$ não pentecostal e $3 \%$ são de uma vertente evangélica indefinida); $3 \%$ são espíritas (2\% kardecistas e $1 \%$ representa os que se definem a partir do Candomblé e da Umbanda); $10 \%$ dos jovens acreditam em Deus, mas não possuem religião e $1 \%$ se declarou ateu. Indagados sobre as questões que mais os preocupam, na atualidade, os jovens apontaram a violência (55\%), o emprego/profissional (52\%) e as drogas (24\%). Em contrapartida, quando indagados sobre os assuntos que mais Ihes interessam, eles elegem a Educação (38\%); o emprego/ profissão (37\%) e a cultura/lazer (27\%). Compreende-se, a partir daí, que, sob o ponto de vista da coletividade ou de questões sociais mais amplas, a violência é o principal problema elencado pela juventude; já sob o enfoque dos interesses pessoais e profissionais sobressai o emprego. É importante ressaltar que educação e trabalho constituem-se como os aspectos principais na vida dos jovens e, por essa razão, tanto podem ser fonte de realização quanto de frustração, tendo em vista que, uma vez não alcançados, esses dois ícones representativos das aspirações juvenis podem, paradoxalmente, expô-los a níveis de vulnerabilidade importantes.

Os informantes mostraram-se otimistas quanto ao potencial de mudança que emana da juventude. Assim, 57\% afirmaram que os jovens podem mudar muito o mundo; $27 \%$ acham que os jovens podem mudar um pouco o mundo; $15 \%$ mostraram-se mais pessimistas, afirmando que os jovens não podem mudar o mundo e $1 \%$ preferiu não responder a questão. É possível sugerir que, não obstante a baixa disposição para o associativismo e a existência de adversidades que atingem boa parte da juventude no país, há uma força no segmento que se coloca como potencialmente geradora de mudanças.

Os dados acima comentados contribuem para apresentar um breve perfil dos jovens brasileiros, mas há que se considerar que os diferentes contextos socioculturais, nos quais muitos deles estão inseridos, podem delinear perfis diversos e, por vezes, contraditórios quando referidos a um determinado padrão nacional. Uma contribuição nessa direção vem da pesquisa que desenvolvi com jovens católicos participantes de paróquias e comunidades, jovens evangélicos de corte pentecostal e não-pentecostal, e jovens sem-religião na Baixada Fluminense região periférica do Rio de Janeiro, que concentra altos índices de desigualdade social (FERNANDES, 2009). Nesse estudo, pude constatar que o local de habitação na cidade faz a diferença na formação de opinião dos jovens a respeito de temas semelhantes aos levantados pela Fundação Perseu Abramo. Por exemplo, nos municípios da Baixada Fluminense, região fortemente marcada pela pobreza e pela baixa infraestrutura educacional, cultural e socioeconômica, os 
jovens com faixa etária similar à investigada pela Fundação são menos católicos, mais evangélicos e muito mais sem-religião. A tabela abaixo demonstra essa distribuição de acordo com o último censo.

8. Elaboração da autora a partir do banco de dados SIDRA IBGE. Acesso em 08 abr. 2009. A tabela foi também citada em Sílvia Fernandes (2009a).

9. A pesquisa sobre a juventude na Baixada Fluminense incluiu, como grupo de controle, os jovens sem-religião e os resultados para esse grupo apontavam para essa interpretação.
Tab. 1 - Distribuição dos jovens de 15 a 24 anos de acordo com a religião nos treze municípios da Baixada Fluminense $-\mathrm{RJ}^{8}$

\begin{tabular}{|l|c|c|}
\hline \multicolumn{1}{|c|}{ Religião } & $\mathrm{N}^{\circ}$ de jovens & $\%$ \\
\hline Católica apostólica romana & 260.433 & 41,5 \\
\hline Evangélicos - de missão & 51.528 & 8,2 \\
\hline $\begin{array}{l}\text { Evangélicos - de origem } \\
\text { pentecostal }\end{array}$ & 110.152 & 17,6 \\
\hline $\begin{array}{l}\text { Evangélicos - outras } \\
\text { religiões evangélicas }\end{array}$ & 8.522 & 1,4 \\
\hline Espíritas & 5.367 & 0,8 \\
\hline Umbanda e Candomblé & 6.313 & 1,0 \\
\hline Outras religiosidades & 14.427 & 2,3 \\
\hline Sem religião & 168.876 & 26,9 \\
\hline Sem declaração & 2.036 & 0,3 \\
\hline Total & 627.654 & 100 \\
\hline
\end{tabular}

Esses dados sugerem que, em condições subalternas, os jovens tendem a não assumir vínculos religiosos institucionalizados, adotando, portanto, a identidade de sem-religião ou, por outro lado, aderindo ao pentecostalismo. Essas escolhas se apresentam de modo simultâneo, abrangendo jovens com trajetórias religiosas distintas ${ }^{9}$.

O catolicismo, embora ainda hegemônico, não atinge sequer a metade da população juvenil nos municípios da Baixada. Assim, poderíamos sugerir que a ausência de qualidade de vida tende a movimentar o jovem em praticamente duas direções, no que tange ao campo religioso: 1) busca de vertentes religiosas emocionais e pragmáticas, tais como o pentecostalismo e/ou as comunidades emocionais; 2) desvinculação que implica em abandono da instituição religiosa, mantendo-se, entretanto, as crenças religiosas ou uma religiosidade composé, de múltiplas facetas.

A diminuição de vínculos da juventude com a Igreja Católica produz um efeito óbvio que é a consequente redução do número de jovens que procuram 
a VR. Mas esta seria apenas uma dentre as constatações possíveis, se levada em conta a hipótese de que a desinstitucionalização religiosa da juventude, no que se refere ao catolicismo, estaria bastante relacionada com a fragilidade das estratégias da Igreja Católica na sensibilização desse segmento. Algumas "ações evangelizadoras" voltadas para os jovens têm sido incrementadas a partir de orientações oficiais da Conferência Nacional dos Bispos do Brasil - CNBB, que atualmente agrega o Setor Juventude. Entretanto, tais ações desenvolvidas pela Igreja Católica tendem a repetir antigas fórmulas ${ }^{10}$, fazendo pouco eco no cotidiano da(s) juventude(s) das grandes cidades.

Historicamente, a Vida Religiosa recrutou jovens de pequenas cidades ou de ambientes rurais, especialmente pela forte tradição católica em algumas regiões específicas do país, como demonstrou Miriam Grossi (1995), em estudo sobre camponeses na região Sul; ou ainda porque essa instituição se apresentava, para os jovens, como uma possibilidade de acesso aos estudos ou mobilidade social, dado que confirmei na pesquisa doutoral (FERNANDES, 2004; 2010). Há muitos jovens religiosos que estão nos Institutos das grandes cidades, mas são oriundos de cidades do interior ou ambientes rurais, nos quais predominam as famílias mais numerosas e certa escassez de ofertas profissionais e educacionais, sobretudo para a juventude.

Ainda que se leve em conta que a intensidade do desejo ou das preocupações dos jovens brasileiros, apresenta variações de acordo com os diferentes contextos sociais, os temas trabalho e educação, como vimos, são pilares das aspirações juvenis e podem se configurar como aspectos da realidade social que catalisam a opção pela Vida Religiosa, principalmente para os jovens de camada social menos favorecida socioeconomicamente. Os institutos religiosos oferecem a possibilidade de estudos e formação profissional aos jovens que neles ingressam, mesmo que os prazos se tornem um pouco maiores em função de que, em alguns casos, os jovens precisarão atender primeiramente às demandas desses Institutos. Tais demandas podem ser pastorais ou relacionadas com o desenvolvimento de obras sociais específicas, necessárias à manutenção da instituição religiosa, tanto no que diz respeito ao cumprimento do "carisma" ou missão fundacional, quanto no que se refere à esfera material e econômica.

Vale sublinhar que as diferenças de gênero determinam os rumos da inserção juvenil na VR tradicional. Enquanto aos rapazes é oferecida uma formação mais sistemática e ampla, às moças é considerada satisfatória, pelos líderes institucionais, a oferta de uma formação baseada no conhecimento da proposta dos fundadores das congregações, o que, numa linguagem nativa, é denominado "carisma". Além disso, elas aprendem um pouco de Teologia, muitas vezes oferecida nos cursos das dioceses e, geralmente, em tempo posterior aos votos religiosos, Ihes é oferecida a possibilidade de cursar o nível superior em áreas
10. Um bom exemplo sobre a dificuldade de formulação metodológica e compreensiva da Igreja sobre a Juventude está no Documento da CNBB intitulado Evangelização da Juventude - desafios e perspectivas pastorais (CNBB, 2007). Ali se repetem e se atualizam antigas fórmulas marcadas por palavras como "conscientizar", "formar" e "orientar" a juventude. 
11. Os dados dessa seção têm base em minha pesquisa intitulada Perspectivas sócio-históricas do Franciscanismo - modernidade $e$ vocação religiosa a partir da "Toca de Assis", que conta com o apoio FAPERJ e CNPq/Pibic. Agradeço a contribuição dos bolsistas Luisa Barbosa Faria e Leandro Gama Omena e, ainda, dos alunos Geziel Zago Sousa, Bruno Marinho e Elizabeth Souza, graduandos do curso de História da UFRRJ.

12. Não há dados atualizados sobre os processos de institucionalização de movimentos ou grupos religiosos no catolicismo que eventualmente tenham se tornado Institutos religiosos, nem estatísticas atuais sobre contingente religioso, em função da interrupção do Censo produzido pelo Centro de Estatística Religiosa e Investigações Sociais, no período 2003-2008, conforme mencionado anteriormente.

13. No corte tipo tonsura, o cabelo é cortado no alto da cabeça e na parte baixa, preservando os fios apenas em torno da cabeça, formando um círculo. que favoreçam a atuação em obras da própria congregação. Assim, se o "carisma" do Instituto religioso é Saúde, as jovens são estimuladas a cursar enfermagem ou outro curso correlato; se o "carisma" é Educação, elas são estimuladas a fazer pedagogia e assim por diante.

A despeito dessas considerações, seria reducionista a proposição de uma leitura da opção juvenil pela Vida Religiosa, na atualidade, a partir do uso de uma única lente que enxergaria, nessa instituição, o trampolim para a mobilidade social de jovens com baixo capital social. Desse modo, embora seja tentador sugerir que os seminários e conventos se apresentam como uma opção interessante para os jovens pobres, na medida em que lhes oferece um mundo de possibilidades materiais, os ares da modernidade contemporânea inspiram novas interpretações para essas escolhas, sobretudo se nos detivermos sobre o curioso caso de jovens que têm buscado a instituição católica e a VR, ingressando na Toca de Assis, instituto religioso brasileiro que abordarei a seguir. Nesse caso, originalmente, foram os jovens de camadas médias que ingressaram e muitos deles não eram provenientes de cidades pequenas e menos desenvolvidas, mas sim das grandes cidades. A maioria desses jovens possui um bom nível de escolarização. Os desafios enfrentados pela VR tradicional diante da novidade das novas comunidades, inclusive em termos do perfil dos jovens que a elas aderem, é o tema que abordarei na seção que se segue.

\section{A VR diante das novas comunidades religiosas - o caso da Toca de Assis ${ }^{11}$}

Caminhar pelas ruas da Lapa, no centro do Rio de Janeiro, é defrontar-se com um quadro curioso ilustrado por jovens envolvidos em sua túnica, descalços ou de sandálias havaianas, cuidando de mendigos, conversando com menores de rua, cortando cabelos ou unhas dos que vivem nas ruas da cidade. São os "toqueiros", ou os jovens da Toca de Assis. O Instituto dos Filhos e Filhas da Pobreza do Ssmo. Sacramento, mais comumente conhecido como Toca de Assis, constitui uma comunidade religiosa de inspiração franciscana, fundada pelo padre Roberto Lettieri que, à época (1994), era seminarista. Esse Instituto, que nasce como comunidade religiosa, não está inscrito em nenhuma das Ordens franciscanas e, até o ano de 2005, não estava cadastrado no Anuário Católico do Brasil ${ }^{12}$.

Em relação aos trajes e à uniformização da aparência física, tão logo se consagram, os rapazes e moças da Toca de Assis passam a usar vestes de cor marrom, no estilo de túnicas similares às usadas pelos primeiros franciscanos. As moças cortam os cabelos bem curtos e os rapazes fazem a tonsura ${ }^{13}$. Há, portanto, uma ambiguidade de gênero e muitas meninas são confundidas com meninos, 
conforme demonstrou Flávia Pinto (2007). Quanto a outras características, há uma tendência de forte rejeição aos estudos acadêmicos e, portanto, rejeição à busca do conhecimento como um valor. Os jovens desenvolvem uma espiritualidade voltada para o atendimento à população em situação de rua e para a experimentação de privações materiais, estimulando o cultivo da pobreza; possuem momentos intensos de oração e prática eucarística, colocando a hóstia ou - conforme a tradição católica -, o "Cristo Sacramentado" como centro da vida espiritual. A Toca de Assis caracteriza-se, ainda: a) pela existência de menor assimetria nas relações de gênero, no sentido de que as moças e os rapazes desenvolvem conjuntamente algumas atividades no interior das casas de assistência à população de rua; b) por recrutar principalmente jovens de camadas médias, contrariando a tendência da VR tradicional, marcada pelo recrutamento de jovens de camadas populares; e c) pela espontaneidade das relações intrainstitucionais. A juventude dos membros é um dos aspectos que mais chama a atenção dos analistas e, segundo o próprio fundador, teria sido o elemento motivador principal para a sua fundação, conforme observou Cecília Mariz (2005).

Entre os jovens da Toca de Assis, o conhecimento de qualquer natureza é tradicionalmente rejeitado e o fundador do Instituto possui claramente uma espiritualidade própria das comunidades emocionais oriundas do chamado revival religioso, cuja RCC é a principal protagonista no catolicismo. Os jovens da Toca de Assis tendem a abandonar os estudos em nível superior e defendem a ideia de que "todo conhecimento vem de Deus".

Tanto a recusa ao conhecimento, quanto a indiferença em relação ao consumo e aos bens materiais colocam esses jovens religiosos em situação diametralmente oposta àqueles que aderem à VR tradicional. Estudo e segurança econômica não se apresentam como catalisadores da opção religiosa dos rapazes e moças da Toca, que possuem uma espiritualidade pautada em três pilares: eucaristia, pobreza e castidade. Conforme mencionei anteriormente, muitos dos jovens são oriundos de famílias de camadas médias e cursavam nível superior antes de abandonarem o estilo de vida que levavam, bem como suas famílias, e ingressarem no Instituto. A maioria é simpatizante da RCC seja pelo que conhecem das comunidades de aliança e vida, seja por terem participado de grupos de oração cultivando uma espiritualidade que se caracteriza pelo intimismo religioso e pela ação social de caráter beneficente.

Curiosamente, a menção a São Francisco de Assis é rara. Destaque-se que, embora sendo de inspiração franciscana, o Instituto elegeu, ainda, mais três santos patronos além de São Francisco. São eles: Santa Catarina de Siena ${ }^{14}$, São Pio de Pietrelcina ${ }^{15}$ e Beata Alexandrina ${ }^{16}$. Esse pode ser um fato que estabelece uma relação importante com a quase total ausência do nome de São Francisco de Assis e de Santa Clara no site e materiais de divulgação da Toca de Assis. A
14. Essa santa foi declarada Doutora da Igreja, pelo papa Paulo VI. Nascida no ano de 1347, vinculou-se à Ordem de São Domingos. Segundo a tradição, a partir de uma visão espiritual, recebeu os estigmas da crucificação.

15. Nascido em 1887, ficou conhecido como Padre. Pio ou o Frei estigmatizado por ter recebido, segundo a tradição católica, os estigmas da crucificação de Cristo. O santo era padre na Ordem dos Capuchinhos.

16. Alexandrina de Balazar viveu no início do século $\mathrm{XX}$ e recebeu o título de beata em 2004. Vítima de uma paralisia ocasionada por uma queda voluntária do prédio onde vivia, a fim de defender sua virgindade, teve como principal carisma a adoração da eucaristia. A história é sintetizada no site da "Toca de Assis" (Cf. site na referência bibliográfica). 
17. $\mathrm{Na}$ tentativa de obter números atualizados sobre o quantitativo de rapazes e moças que integram, hoje, a Toca de Assis fiz contato com os responsáveis pela Pastoral vocacional da Toca e obtive os seguintes dados por telefone, em meados de 2009: número de moças 1.236; número de rapazes: 550 . Esse número sobre os rapazes contrasta com aquele fornecido no site à época da consulta feita, em 2008. Fiz nova atualização dessa informação em outubro de 2010, a partir do contato com o setor de Comunicação da Toca, e obtive os seguintes números de seguidores em nível nacional: 449 jovens moças e 211 jovens rapazes. Embora seja observada uma redução no número de jovens, nota-se que há uma presença feminina significativa se compararmos com o total nacional de noviças conforme mencionado na primeira parte deste artigo. escolha daqueles santos como patronos sugere uma valorização do sofrimento físico como ascese, já que dois santos teriam recebido estigmas, além da valorização da eucaristia, elemento fortemente presente na espiritualidade dos "toqueiros". Nesse sentido, os membros da Toca de Assis realizam o ascetismo ativo, que supõe a ação do indivíduo no mundo como instrumento divino e o misticismo que o coloca como recipiente do divino. Conforme Weber (1982), se o místico contemplativo não conclui que deve fugir do mundo, mas nele atuar, o contraste entre o misticismo e o ascetismo diminui significativamente. A eleição dos santos patronos denota, portanto, a conciliação entre ascetismo e misticismo na experiência dos jovens membros do Instituto Toca de Assis.

Quanto à distribuição territorial da instituição, há Casas ou "Fraternidades" da Toca em catorze estados brasileiros e em quase todas as regiões. Apenas na região Norte ainda não há fundações. No exterior, há casas no Equador e em Portugal (neste há apenas casas femininas). Segundo informações fornecidas no site, cerca de oitocentos rapazes pertencem ao Instituto e, embora haja o registro da existência de quarenta e seis casas femininas, não há dados sobre o número de moças que ingressaram na Toca de Assis ${ }^{17}$. Se, por um lado, esses números revelam a forte capacidade da Toca em atrair a juventude, cabe mencionar que há também desistências. Alguns entram, mas não permanecem e, enquanto uns entram, outros saem dando ao Instituto um perfil altamente dinâmico, todavia, simultaneamente instável.

A história mostrou que tanto Francisco quanto Clara de Assis foram revolucionários em seu tempo, na medida em que tiveram de experimentar, no âmbito privado, o descontentamento dos familiares e, no âmbito público, os constantes confrontos e negociações com a Igreja romana do medievo. A rigidez da Igreja medieval com as Ordens religiosas impunha que novas comunidades religiosas se integrassem às existentes, mas não houve, por parte de Clara, uma adesão inconteste a essa orientação, conforme demonstrou Delir Brunelli (2003). Enquanto os conventos da época primavam pelos altos dotes e pela riqueza, os fundadores do Franciscanismo defendiam a renúncia de bens de qualquer natureza. A experiência da pobreza ou da capacidade de renunciar a bens materiais tornou-se, assim, um importante bem simbólico na Vida Religiosa e um dos principais indicadores de vocações autênticas para os fundadores e superiores das Ordens.

Sabe-se, contudo, que o Franciscanismo nem sempre foi fiel a esse ideário. Não raro, a experiência de não possuir bens fora relativizada, na medida em que muitas congregações de inspiração franciscana reinterpretaram o "mandamento", de modo que aquele que ingressava não poderia possuir bens pessoais, mas estes seriam transferidos ou delegados à Ordem religiosa. Mas será que o ideário de vida da Toca de Assis seria uma espécie de retorno às origens, 
ou "Refundação18"? Estaria a proposta do Instituto de promover uma conduta pautada na pobreza, no questionamento e, de certa forma, na rejeição a modelos de VR tradicionais sendo indicadora de uma contestação aos valores colocados pela sociedade moderna? Para Rodrigo Portella, a Toca pode se configurar como um "protesto contra certa faceta da Igreja que comunga com a modernidade racional e desencantada" (PORTELLA, 2009, p.192).

Interessa notar que, embora o ideal de pobreza, austeridade e "abandono à Providência"19 enfatizado pela Toca de Assis esteja muito presente em seu discurso, no site do Instituto há uma loja virtual, onde são comercializados produtos religiosos (terços, peças artesanais, chaveiros com motivos religiosos, CDs, etc.), havendo, contudo, uma justificativa onde se lê que os produtos são exclusivos e que, ao adquiri-los, se está contribuindo para as obras de assistência social. Uma hipótese que tenho explorado em minha pesquisa com esses jovens diz respeito, exatamente, às representações acerca da pobreza ou o elogio à pobreza, além do que pode ser pensado como uma outra dimensão de austeridade por eles pretendida: a contestação do conhecimento acadêmico. O trabalho de campo evidenciou a simplicidade das casas e a ausência de indicadores do que seria o cultivo ao consumo mercadológico ou próprio de nossas sociedades capitalistas. Simultaneamente, nota-se certo desconhecimento dos membros sobre a amplitude do trabalho da Toca, seja por meio da Internet, seja em outros países.

Em entrevista com um jovem responsável por uma casa de acolhida no Rio de Janeiro, observei que não há uma visão global das ações institucionais da Toca de Assis por parte de seus seguidores. Assim, os membros podem desconhecer, por exemplo, que a Toca de Assis está presente na internet, em sites de vídeos como o Youtube, ou até mesmo em sites de relacionamento, como o Orkut. Perguntado sobre a presença do Instituto nesses meios, um de meus informantes demonstrou seu desconhecimento: "É mesmo? Eu não sabia disso. Em que sentido?" (Ir. J. 28 anos). Não se torna plausível inferir que o fato de a Toca de Assis arrecadar recursos por meios eletrônicos ou fazer propaganda de seus produtos signifique uma flexibilização da experiência da pobreza como virtude. Talvez se possa sugerir, antes, que há esferas de circulação do consumo no Instituto e que a vida privada dos membros da Toca não comporia essa esfera. Por outro lado, temos observado que o Instituto passa por um processo de racionalização provocado, sobretudo, a partir do afastamento do padre fundador, Roberto Lettieri (FERNANDES, 2011).

Segundo a tradição sociológica de Berger e Luckmann (2004), se as instituições são capazes de atribuir sentido à ação do indivíduo nos mais diversos campos da vida social, elas terão mais chances de sobrevivência. Para esses autores, algumas Ordens religiosas ou Comunidades de Vida ${ }^{20}$ cumprem essa função de significação da vida e variam na gradação de um mínimo ou um máximo de
18. Essa terminologia tem sido bastante utilizada na literatura teológica da VR e sugere aprofundamento e atualização dos carismas fundacionais de acordo com as exigências atuais.

19. As Comunidades de vida agregam leigos que se consagram e vivem a castidade. É uma nova tendência de orientação carismática que surge no cenário brasileiro, de modo mais intenso na década de 1990. Há estudos sobre comunidades de vida específicas, como é o caso da Canção Nova, estudada por Eliane Oliveira (2003).

20. As Comunidades de vida agregam leigos que se consagram e vivem a castidade. É uma nova tendência de orientação carismática que surge no cenário brasileiro, de modo mais intenso na década de 1990. Há estudos sobre comunidades de vida específicas, como é o caso da Canção Nova, estudada por Eliane Oliveira (2003). 
sentido. Os estudos empíricos e teóricos que venho realizando demonstram que há diversificações nos sentidos que foram dados à pobreza no Franciscanismo primitivo e na VR tradicional e nos significados que os membros da Toca atribuem à pobreza, mas, simultaneamente, há linhas que se entrecruzam entre os vários modelos de VR no que diz respeito a essa diversidade de sentidos.

Um jovem relatou-me que cuidar das feridas dos pobres significava, para ele, assumir a própria pobreza diante do Cristo no sentido de que o pobre representaria a figura do Cristo que pedia para ser cuidado. Esse jovem garante que cada vez que cuida das feridas de um mendigo ou um idoso abandonado nas ruas sente que não é merecedor dessa honra: "cuidar do próprio Cristo na pessoa dos pobres". Essa reflexão - profundamente fundamentada nas narrativas religiosas bíblicas, - está carregada dos sentidos de pobreza que sugerem despojamento de si; noção própria da VR tradicional, mas que, entre os jovens da Toca, assume a radicalidade da abstinência material de modo bem mais intenso do que entre os jovens religiosos que vivem na segurança e no conforto de suas casas e, eventualmente assistem aos pobres. Muitas vezes, ouvi das noviças que viver o voto de pobreza era não possuir nada seu, mas ter tudo em comum, e ouvi de noviços vinculados à VR tradicional que viver esse voto era não se apegar a coisas materiais:

(...) eu não me apego tão fácil a coisas materiais, a lugares. Nesse sentido eu tive facilidade de viver o voto de pobreza. (...) eu lembro que a maior dificuldade que eu tive de viver a pobreza acho que foi uma vez que ganhei uma chuteira, quer dizer, eu ganhei duas chuteiras, pra ver como são as coisas... A gente joga futebol, então eu ganhei uma chuteira, só que era um pouco grande para mim e eu dei pro meu amigo. Daí esse amigo meu ganhou uma chuteira, deu pra mim e eu ganhei outra, então [foram] duas chuteiras novas na mesma semana, ali. Daí eu apresentei pro Frei [reitor] e eu estava precisando; daí quando ganhei a segunda, fui apresentar pro Frei, daí ele falou: C., você está precisando? Eu falei: eu estou precisando. Peguei a chuteira e voltei pro quarto. Ah, no outro dia eu voltei lá e falei: Ó, não estou precisando... pesou a consciência, daí deixei lá. (rapaz em fase de noviciado, 28 anos, VR tradicional)

O dilema vivido por esse jovem pertencente à VR tradicional sequer se coloca para um rapaz da Toca de Assis. Nas rotinas das casas de acolhida, por exemplo, eles dormem no chão, nos intervalos das camas onde dormem os doentes, pobres e mendigos; andam descalços ou de sandálias, como mencionado anteriormente, e ficam ao final da fila do almoço aguardando que todos os moradores acolhidos na casa se sirvam e, só então, os toqueiros se aproximam para as refeições. Muitas vezes, em razão dessa prática, não Ihes sobra a "mistura", 
ou o que seria a proteína da refeição.

O exemplo comparativo das representações dos jovens religiosos sobre a pobreza quer ilustrar que há similaridades e afastamentos na experiência de ambos os modelos de VR, mas certamente a radicalização da Toca e a atitude de despojamento dos jovens vinculados à VR tradicional são expressões claras de algumas tendências geracionais: "vontade de ruptura" ou contestação do cotidiano; crença na transformação da sociedade a partir de práticas individuais, ascéticas e radicais, que conjugam carismatismo com o espírito da juventude; e, por fim, autorrepresentação heroica. Se lembrarmos o dado apresentado na primeira seção a respeito do otimismo dos jovens sobre o potencial da juventude para promover mudanças, veremos que "ser pobre" para os jovens que aderem à vida consagrada, em seus diferentes estilos, possui uma conotação heroica, porque demandaria coragem no enfrentamento da tendência cultural vigente.

O trânsito ou circulação dos jovens pelas várias possibilidades de vivência de experiências radicais na VR fica patente quando se analisa o depoimento de uma jovem religiosa que atualmente pertence à Ordem das Clarissas, mas que anteriormente fora membro da Toca de Assis.

(...) Realmente quando nos calamos Deus fala. Neste encontro conheci várias congregações. Conheci a Toca de Assis e me encantei comecei a visitar suas casas, fazer pastoral de rua, porém, novamente senti aquela inquietação. Uma amiga me falou que na Canção Nova em Cachoeira Paulista havia um mosteiro de Clarissas, mas, o que é uma Clarissa? Quando conheci as Clarissas, o mosteiro, o coração bateu mais forte, contudo, a razão falou mais forte. Ficar fechada, longe das pessoas de quem gosto e em silêncio. Não, eu não vou ser Clarissa. Nosso coração só se acalma quando fazemos a vontade de Deus. Tentei fugir de todos os modos, mas não consegui. Quando Deus nos chama não há lugar no mundo onde se possa esconder. (Ir. Ana Beatriz) ${ }^{21}$

O depoimento da jovem religiosa indica que há que se ter cuidado com as simplificações analíticas a respeito das propostas aparentemente antagônicas da Toca de Assis e de uma Ordem de clausura. A ideia de um destino vocacional, manifestada na expressão "tentei fugir de todos os modos, mas não consegui", aparece no depoimento como o elemento motivador para a opção da jovem. A crença nesse destino vocacional pode ser analisada, entretanto, considerandose os discursos de recrutamento das congregações. Em estudos que realizei em congregações de vida ativa, observa-se, de modo semelhante, a ideia de um apelo inenarrável e irrefutável do divino a seu escolhido (FERNANDES, 2004). Essa jovem afirma que, apesar de achar que não seria uma atitude muito racional abandonar a Toca para ingressar na clausura, acabou não resistindo a 
essa proposta, fato que denota sua opção pela radicalidade da clausura. Não é difícil imaginar, contudo, que a experiência religiosa dos "toqueiros", que supõe um mundo de privações, apresentaria maiores dificuldades e privações do que a vida conventual.

Em razão dessas diferenças, há estranhamentos mútuos entre a Toca de Assis e a Vida Religiosa tradicional. Os toqueiros sentem que "incomodam" por sugerirem, a partir de sua espiritualidade radical, que a VR abandonou seus ideais primeiros de testemunho e inadequação ao mundo. Por sua vez, muitos membros religiosos da VR tradicional acreditam que a experiência da Toca de Assis pode conduzir ao fanatismo ou fundamentalismo religioso, temem pela diminuição ainda mais intensa de candidatos e candidatas para seus institutos religiosos e buscam alguma aproximação com membros que assumem funções de coordenação na Toca de Assis, convocando-os para encontros regionais de formação.

O principal desafio que a Toca de Assis coloca para a VR tradicional é a sua juventude, pois sendo um Instituto religioso brasileiro fundado há apenas 17 anos ainda não experimenta, com toda a sua força, a rotinização do carisma e o forte enquadramento das relações comunitárias, elementos fortemente presentes na maioria das congregações religiosas, especialmente as de origem europeia. A prática religiosa acontece na Toca juntamente com a disponibilidade e espontaneidade de seus membros, que ingressam no Instituto com altos níveis de idealismo. Ainda que se admita que os dirigentes da Toca de Assis buscaram rapidamente a institucionalização do movimento, o cotidiano das casas e as atividades próprias do Instituto os colocam como silenciosos questionadores da tradição e óbvios manifestantes de novas possibilidades de experimentação do religioso no mundo contemporâneo. Nesse sentido, esse instituto, religioso, que surge como uma comunidade de vida, confirmaria uma tendência do segmento juvenil em contestar a ordem social ainda que por meios não necessariamente políticos. Eles parecem reagir à condição dada à juventude na sociedade brasileira. A avaliação de possíveis consequências desse tipo de afastamento da vida produtiva e do campo educacional formal está sendo realizada a partir dos dados de campo e será discutida em outro texto.

O uso e a construção do poder na VR - algumas notas sobre as relações comunitárias.

Se existe um campo onde a batalha é cotidiana e permanente, este é o das relações comunitárias na VR. Com pouco esforço se chega à constatação de que a convivência diária não pode ser considerada um "exercício de levitação", seja no trabalho, na família ou em outros grupos sociais. Certamente, não tem 
sido diferente na VR. O exercício da abertura à diferença, tão propalado nas teorias multiculturais, tem sido um tema de grande abrangência na produção teórica e reflexiva da VR tradicional, conforme demonstrado a partir da análise de um dos principais periódicos dos religiosos no Brasil. No ano 2000, 22,2\% dos artigos publicados na Revista Convergência trataram do multiculturalismo e, em 2001, os artigos que abordaram esse tema, no mesmo periódico, corresponderam a $18,6 \%$ (FERNANDES, 2007).

Estudando os jovens candidatos à VR tradicional, constatei que as moças são mais críticas quanto ao exercício do poder na VR e os rapazes bem mais contidos a respeito desse tema, assumindo posições mais consonantes com o discurso oficial. Não é muito difícil constatar as razões dessas diferenças. Além de que são os rapazes que comporão a hierarquia, a eles é oferecida a possibilidade de estudar e projetar-se acadêmica e profissionalmente desde cedo, quando se iniciam, a partir dos centros de formação e seminários, os estudos em filosofia e teologia. Às moças é oferecido o discurso do "serviço" e do exercício do ministério pastoral, que envolve dinâmicas diferentes a partir de cada "carisma" ou prescrição institucional.

Mas seria equivocado inferir que as diferenças de gênero no exercício do poder seriam as principais deflagradoras dos conflitos nas relações comunitárias. $\mathrm{Na}$ verdade, se as diferenças de gênero têm peso nos dilemas institucionais mais amplos, nas relações comunitárias, elas competirão com as diferenças intragênero e intergeracionais. Assim, há muita disputa e competição entre as mulheres mais jovens e as mais maduras na VR e essas disputas ficam fortemente evidenciadas a partir das diferentes funções assumidas e dos distintos lugares institucionais. Nessa dinâmica, superiores e formandos em diferentes etapas formativas performam o conjunto com maior potencial de tensão institucional.

Os jovens que já fizeram os votos religiosos na VR tradicional, com os quais mantive contato, são críticos, por exemplo, ao que denominam de "etapismo" na fase formativa da VR e ao que consideram um recrutamento de candidatos baseado na lógica quantitativa. Rapazes e moças tendem a problematizar a formação atual, que leva pouco em conta os contextos socioculturais e as mudanças de época e, o que seria o pior dos males, pouco considera as demandas de sentido apresentadas pelos jovens religiosos. A formação na VR estaria, portanto, mais concentrada na transmissão dos carismas e na manutenção da tradição de forma inconteste. Além disso, há muitas queixas dos jovens sobre o mau uso do poder por parte dos formadores e reitores.

Essa visão institucional produz recriminações à juventude que ingressa na VR. Algumas moças são convocadas a mudarem seus hábitos de convivência doméstica, devendo assumir postura mais formal no interior das congregações. 
Recato e compostura são exigidos da jovem noviça na maioria das casas religiosas -, hoje raramente denominadas de conventos - e opiniões sobre os destinos institucionais, com raras exceções, não são permitidas às jovens religiosas. Esse quadro se repete no universo masculino, com poucas variações.

Ao mesmo tempo em que são críticos quanto à rigidez ou fechamento institucional, ou ao que um rapaz chamou de "medo do autoconhecimento" referindo-se à VR, alguns jovens "junioristas", como são chamados os que possuem poucos anos de profissão dos votos religiosos, reconhecem que nem sempre aproveitam as oportunidades de participação nas mudanças institucionais, quando essas lhes são oferecidas. As tensões entre manter e renovar, entre avançar e retroceder, constituem o cerne da crise da VR tradicional, que tem se mostrado mais lenta e reticente na implementação de mudanças, fazendo uso de um poder instituído que pode voltar-se contra a própria instituição.

Há pouco tempo, um instituto religioso feminino me fez uma consulta sobre a possibilidade de ajudá-los no conhecimento do que seria uma análise institucional. O quadro era o seguinte: religiosas idosas, instituto religioso centenário e com pouquíssimas novas candidatas. Crise de relacionamentos comunitários, crise de gestão das empresas ou "obras" - naquele momento sendo desenvolvida praticamente apenas por leigos -, crise de identidade. Ao final de um dia de explanação a um pequeno conselho de religiosas, ficou patente o medo da mudança que poderia ser provocada se optassem por realizar uma avaliação institucional. As religiosas me agradeceram a assessoria e ficaram de avaliar, um pouco mais à frente, a possibilidade de implementar, em sua congregação, uma análise daquela natureza. Encontrei, meses depois, uma jovem religiosa dessa congregação em um seminário acadêmico. Quando perguntei pela decisão a que as irmãs teriam chegado, ela informou-me que houve um medo generalizado de realizar a avaliação institucional, fato que ela própria lamentou profundamente, pois tinha plena convicção da necessidade de efetivação das mudanças institucionais.

O medo da mudança e da renovação tem tido, como efeito, a perpetuação de relações de poder assimétricas na VR e que não condizem com o ideário religioso proposto pelas próprias instituições. Tal incongruência pode produzir o afastamento, por parte de muitos jovens que visavam seguir esse estilo de vida. Por outro lado, institutos religiosos novos e idealistas tendem a atrair mais jovens e a ameaçar o processo de reprodução e sobrevivência das congregações tradicionais. Se o destino inexorável das novas comunidades religiosas for a rotinização do carisma, nos moldes weberianos, a manutenção da VR enquanto instituição fica ameaçada pela permanente tensão com o mundo moderno. Por outro lado, a adesão juvenil a institutos como a Toca de Assis produz questionamentos importantes, tanto ao que pode ser entendido como senso comunitário em 
nossa sociedade - uma vez que os jovens parecem buscar estilos de vida agregadores e integradores -, quanto no que diz respeito à própria condição juvenil e aos novos valores que vêm sendo formatados a partir da experiência religiosa.

A promoção de canais de diálogo fora e dentro das instituições que têm como seus integrantes principais os jovens pode ser uma importante ação na direção desse segmento que demanda sempre novas experiências. Essas demandas podem ser observadas na medida em que, na sociedade brasileira, tem se intensificado um processo de adesão juvenil a propostas religiosas alternativas aos sistemas religiosos oficiais. A compreensão desse processo exige abertura e disposição dos analistas. As novas sensibilidades religiosas juvenis constituemse como fontes de potencial revigoramento de um universo religioso historicamente instituído e se coloca como um significativo desafio analítico.

Abstract: The article examines the contemporary youth from the axis of the religiosity and religious adherence to Catholic institutions. The first section presents data on the profile of young people and shows that work and study are important demands to this segment. The young Brazilians also express belief in social change. Based on data of a quantitative research with young religious, in Baixada Fluminense, and primary data on young people in the Institute Toca de Assis, the second part of the article argue that the latter young, coming from its ideals of poverty and denial of the knowledge, can represent a challenge to situation of the young Brazilian society. It compares the different forms of adherence to religious institutions and suggests that Toca de Assis, in spite of the institutionalization process that it goes through, has challenged the traditional institutions of religious life and its mechanisms of power and is presented as an empirical object relevant to the analysis of new religious sensibilities of the youth.

Keywords: Contemporary Youth, Religious Life, Catholicism, Power, Toca de Assis.

\section{Referências Bibliográficas}

AZZI, Riolando. História dos religiosos no Brasil - enfoques históricos. São Paulo: Paulinas, 1983.

BERGER, Peter; LUCKAMN, Thomas. Modernidade: pluralismo e crise de sentido - a orientação do homem moderno. Petrópolis/RJ: Vozes, 2004.

BRUNELLI, Delir. "Clara de Assis e o movimento religioso feminino nos séculos XII e XIII" In: S. Costa; A. C. L. F. da Silva; L. R. Silva (orgs.) Atas do Ciclo A Tradição Monástica e o Franciscanismo. Instituto de Filosofia e Ciências Sociais da UFRJ IFCS, mimeo, 2003.

CNBB. "Evangelização da Juventude - desafios e perspectivas pastorais". Documentos da CNBB, n. 85, São Paulo: Paulinas, 2007. 
FERNANDES, Sílvia R. A. "Racionalização religiosa em tempos de pluralismo - o caso da Toca de Assis". Relatório Científico - FAPERJ, mimeo, 2011.

. Jovens religiosos e o catolicismo - escolhas, desafios e subjetividades. Rio de Janeiro: Quartet/Faperj, 2010.

. Juventude, religião e política na Baixada Fluminense - ações e representações. Relatório científico FAPERJ, mimeo, 2009.

. "Juventude nas Igrejas e fora delas: crenças, percepções da política e (des) vinculações". Revista Tomo, n. 14, UFS. 99-126, 2009a.

. "Interfaces entre juventude e vocação: uma análise qualitativa no Rio de Janeiro". Revista Eclesiástica Brasileira, vol. 69, fasc. 274, Petrópolis/RJ: 361-387, 2009b.

. "Impasses da vida religiosa em contexto multicultural - interpelações sociológicas sobre demandas de identidade". Caderno de Ciências Humanas - Especiaria, Ilhéus: Universidade Estadual de Santa Cruz, v. 10, n. 18, jul, 2007, p. 679-701.

. "Ser padre pra ser santo; ser freira pra servir" - a construção social da vocação religiosa. Uma análise comparativa entre rapazes e moças no Rio de Janeiro. 372p. Tese de Doutorado. Programa de Pós-Graduação em Ciências Sociais - UERJ, Rio de Janeiro, 2004.

. Vinho novo em odres velhos? Uma análise da Vida Religiosa feminina na modernidade contemporânea. Dissertação. Rio de Janeiro: Programa de Pós Graduação em Ciências Sociais - UERJ, 1999.

GROSSI, Miriam. "Conventos e celibato feminino entre camponesas do sul do Brasil". Horizontes Antropológicos. Porto Alegre, n. 7, 1995, p. 47-60.

MARIZ, Cecília L.“Missão religiosa e migração: 'novas comunidades' e igrejas pentecostais brasileiras no exterior". Análise Social, vol. XLIV (1.) ), 2009, p. 161187.

. "Comunidades de vida no Espírito Santo-juventude e religião". Tempo Social, Revista de Sociologia da USP, v. 17, n. 2, 2005, p. 253-273.

OLIVEIRA, Eliane Martins. O mergulho no Espírito de Deus: diálogos (im) possíveis entre a Nova Era e a Renovação Carismática Católica na Comunidade de Vida no Espírito Canção Nova. Dissertação de mestrado em Ciências Sociais, UERJ, Rio de Janeiro, 2003. 
. A "Vida no Espírito" e o dom de ser canção nova. Novas Comunidades Católicas - em busca do espaço pós-moderno. Aparecida, SP: Idéias\&Letras, 2009, p. 195-221.

PINTO, Flavia Slompo. "Hexis Sagrada': constructos da juventude vocacionada na Fraternidade 'Toca de Assis'". Relatório de pesquisa Pibic/Cnpq, UNICAMP, 2007.

PORTELLA, Rodrigo. Medievais e pós-modernos: "A Toca de Assis e as novas sensibilidades católicas juvenis". Novas Comunidades Católicas - em busca do espaço pós-moderno. Aparecida, SP: Idéias\&Letras, 2009, p. 171-194.

WEBER, Max. "Rejeições religiosas do mundo e suas direções". Ensaios de Sociologia. Rio de Janeiro: Guanabara, 1982.

Sites consultados:

Toca de Assis: http://www.tocadeassis.com.br. Acesso em 12 fev 2008.

Toca de Assis: http://www.tocadeassis.org.br: Acesso em 25 out 2010. 